\title{
Comparison of Carboxymethyl Cellulose (CMC) and Microcrystalline Cellulose (MCC) as Filler for Sago/Citric Based Bioplastic by Response Surface Methodology
}

\author{
Syelvia P Utami ${ }^{\mathrm{a},}$, , Esty O Sari ${ }^{\mathrm{a}}$, Vivi Novriyani ${ }^{\mathrm{a}}$, Dewi M Sari ${ }^{\mathrm{a}}$, Nor Aishah S Amin ${ }^{\mathrm{b}}$, Bahruddin ${ }^{\mathrm{a}}$ \\ ${ }^{a}$ Department of Chemical Engineering, Universitas Riau, Pekanbaru 28293, Riau, Indonesia \\ ${ }^{b}$ Chemical Reaction Engineering Group (CREG), School of Chemical and Energy Engineering, Faculty of Engineering, Universiti Teknologi \\ Malaysia, 81310, Johor Bahru, Johor, Malaysia \\ Corresponding author: *syelvia.putriutami@lecturer.unri.ac.id
}

\begin{abstract}
Bioplastic material has emerged as one solution to the environmental problem caused by commercial plastic. Several raw materials have been used for bioplastic production, such as cassava, potato, and sago starch. This research focused on studying the effect of fillers and plasticizers variation to tensile strength and its morphology by using sago starch/citric acid-based bioplastic. The comparison of sorbitol and glycerol role as the plasticizer and microcrystalline cellulose and carboxymethyl cellulose as fillers were observed. This study was conducted by mixed and heated sago starch and fillers together. Then, citric acid and plasticizers were employed in the mixture solution. Next, the mixture was heated for $24 \mathrm{~h}$ then molded. The concentration of fillers, plasticizers, and citric acid were used as an independent variable which the interaction among them were investigated using response surface methodology (RSM) based on Central Composite Design (CCD). ASTM D822 evaluated tensile strength, and the morphological analysis was observed by using scanning electron microscopy (SEM). The results showed that the highest tensile strengths were 8.23 MPa for the glycerol and $\mathrm{CMC}$ process and $15.84 \mathrm{MPa}$ for the sorbitol and MCC process. It was found that sorbitol and microcrystalline cellulose (MCC) increased the value of tensile strength twofold more than other fillers and plasticizers. As for the response surface method, the results describe the significant interaction between plasticizer and filler. It showed the tendency of increasing the concentration of fillers and citric acid decreased the tensile strength.
\end{abstract}

Keywords — Bioplastic; citric acid; filler; plasticizer; sago; tensile strength.

Manuscript received 3 Feb. 2020; revised 9 Jul. 2020; accepted 24 Feb. 2021. Date of publication 31 Aug. 2021. IJASEIT is licensed under a Creative Commons Attribution-Share Alike 4.0 International License.

\section{INTRODUCTION}

Plastics have been used for various life fields because it is considered economical, flexible, lightweight, and not easily broken material. This high consumption of plastics made Indonesia suspected as the second-largest country which contributed to plastic pollution, especially in the marine area [1]. It triggered many problems with the environment, not only in marine but also in soil and air. The plastics buried in landfills make the environment more severe because it is hard to degrade and diminish in the soil [2][3]. On the other hand, bioplastics are designed to be environmentally friendly since their carbon footprint is less than conventional plastic. Researchers also found that polysaccharides as a material source of bioplastic have been scrutinized for their biodegradable ability, and thermoplastic properties have become more fascinating in the material field [4]. One of the bioplastics materials that are easily broken down by microorganisms is starch. In addition to its biodegradable nature, starch is a natural resource which renewable and has affordable prices, which makes starch is a promising material to be used as a matrix with reinforcements and fillers to form biopolymer [5] [6][7].

Sago (Metroxylon spp) has predominant starch, which grows in freshwater swamp areas, peat swamps, areas along rivers, areas around water sources, or swamp forests. Indonesia is one of the broadest sago plantations globally that spread out from West Papua to Aceh and Riau Province [8]. Sago has a similar physicochemical of starch like cassava and potato. Amylopectin content in the sago starch positively affects tensile strength, which makes this material suitable as bioplastic's source [9].

One application of bioplastics is edible film. However, this starch-based edible film also has some disadvantages, like 
weak mechanical and barrier properties. Besides, it has high water vapor permeability and high brittleness, which undesirable for packaging used. Therefore, plasticizing agents and filler help to minimize this condition [10], [11]. Bioplastics or biodegradable plastic still have some disadvantages compared to conventional plastics; those are mechanical properties that are easily torn and not as strong as conventional plastic. Some research has been carried out to develop sago starch-based bioplastics' ability to have superior properties by combining starch with other polymers.

Ghanbarzadeh et al. [12] studied the physical properties of edible films with modified starch-carboxymethyl cellulose (CMC). The best results in this study were $15 \% \mathrm{w} / \mathrm{w}$ of carboxymethyl cellulose (CMC)/starch. It caused decreasing in moisture absorption and film solubility from $24.34 \%$ and $23.76 \%$ to $20.00 \%$ and $19.89 \%$, respectively. Zuraida et al. [13] also reported a study with the effect of water and citric acid on sago starch-based bioplastics. They varied glycerol and citric acid concentration and weight percentage of waterbased on $100 \%(\mathrm{w} / \mathrm{w})$ sago starch. The results showed that the optimum tensile strength for the composition of sago and glycerol was $23.06 \mathrm{MPa}$, the composition of sago starchglycerol and citric acid was $24.766 \mathrm{MPa}$. Aquades as an additive in sago starch-glycerol has an optimum tensile strength of $3.29 \mathrm{MPa}$.

Wilpiszewska and Czech [14] conducted a modification of citric-starch potatoes with microcrystalline cellulose (MCC) amplifiers with variations of $\operatorname{MCC}(1,3,5,7,10$, and $15 \% \mathrm{w} / \mathrm{w})$. The results exhibited that the addition of microcrystalline cellulose (MCC) increased the polysaccharide film's mechanical properties. The young's modulus and tensile strength increased from 42 to $96 \mathrm{MPa}$ and 2.6 to $3.9 \mathrm{MPa}$, respectively for non-filled starches or citric acid films and the same system containing $15 \% \mathrm{w} / \mathrm{w}$ MCC. In addition, cellulose fillers' presence influencing the thermal properties of starch-based materials by increasing the transition MCC glass content increased from 108 to $129{ }^{\circ} \mathrm{C}$, each for non-filled starch or citric acid films and the same system having $15 \% \mathrm{w} / \mathrm{w}$ MCC. Also, starch-based films' hydrophilicity properties are reduced because the absorption of moisture and solubility in water decreased.

Another study investigated the concentration of plasticizer on mechanical and barrier properties of sweet potato starch film. The high concentration of plasticizers such as glycerol and sorbitol can reach high water solubility and elongation percentage. The contrary results showed that plasticizer's increased concentration could decrease the puncture strength value [15].

Citric acid has been used as a cross-linking agent, which non-toxic, low cost, and able to stabilize the polysaccharide material. Several studies about the ability of citric acid as a cross-linking agent have been reported [14], [16], [17]. Priyadarshi et al. [16] reported that citric acid employment decreased moisture content and water absorption and generated the water vapor barrier. Meanwhile, another study mentioned the less concentrated citric acid produced a good cross-linking agent for polysaccharides [17]. Besides, Ma et al. [18] mentioned that citric acid concentration has also influenced edible film's mechanical properties. Based on previous research, which generally developing the mechanical and properties of bioplastics, varying composition of raw materials, plasticizers and fillers were used. However, the mechanical, morphological, and biodegradability characteristics produced are not consistent with the different types and compositions of plasticizers, fillers, and raw materials used. Therefore, this study aimed to investigate the effect of glycerol and sorbitol as a plasticizer and microcrystalline cellulose and carboxymethyl cellulose as fillers for sago-based bioplastic. Response surface method was applied to evaluate the interaction between plasticizers and fillers towards tensile strength.

\section{MAterial AND Method}

\section{A. Material and Apparatus Tools}

The raw material used in this study was sago starch originating from the Selat Panjang region, Meranti Islands. The fillers were microcrystalline cellulose (MCC) and carboxymethyl cellulose (CMC), sorbitol, and glycerol as a plasticizer were purchased from Brataco Chemika Inc. (Indonesia), and citric acid was purchased from Putra Riau Bersama (PRB, Indonesia) and aquadest. The equipment was analytical balance, beaker, volumetric flask, goblet glass, measuring cup, stirring rod, oven, filter, glass mold, watch glass, heating mantle, condenser, triple neck flask, thermometer, and hot plate.

\section{B. Methods}

- The procedures are divided into two parts. There is the preparation of filler solutions and bioplastic mold. The brief procedure is shown in Fig. 1.

1) Preparation of Microcrystalline Cellulose and Carboxymethyl Cellulose Solution: MCC with concentrations 15,20 , and $25 \%$ (w/w starch) was placed with $100 \mathrm{~g}$ water in a flask and mixed for 30 min using a mechanical stirrer at $90^{\circ}$ $\mathrm{C}$ until a homogeneous MCC solution was formed. Meanwhile, for the CMC, it is homogenized with $100 \mathrm{ml}$ equates at $75^{\circ} \mathrm{C}, 100 \mathrm{rpm}$ for $15 \mathrm{~min}$.

2) Preparation of Bioplastic: Dissolved $10 \mathrm{~g}$ of sago starch with $100 \mathrm{ml}$ of distilled water in beaker glass at room temperature $\left(25^{\circ} \mathrm{C}\right)$. Then, added the MCC solution. The mixture was stirred around $200 \mathrm{rpm}$ and heated up at $90{ }^{\circ} \mathrm{C}$ (kept it constant) after 20 min sorbitol was employed. Citric acid was added at $25^{\text {th }} \mathrm{min}$. The total process was conducted for 30 minutes. The homogeneous solution was stand for \pm 5 min, then it was poured into the mold for 24 hours. Once it dried, the plastic film was released from the mold by lifting a thin sheet from one side of the horizontal direction slowly until the entire bioplastic surface was detached from the mold. Afterward, bioplastics were tested for characteristic and mechanical properties - repeated procedures for variations of citric acid levels, sorbitol plasticizer levels, and MCC filler levels. Also, for CMC and glycerol variations.

\section{Bioplastic Characteristics Test}

The characteristic tests were conducted to analyze the mechanical and morphological properties.

1) Mechanical Properties: Characterization of the mechanical properties of bioplastics included tensile strength, modulus young, and elongation. This mechanical property 
test refers to the ASTM D822 standard with 2 × $6 \mathrm{~cm}$ sample size test specimens.

2) Morphological: The structure of bioplastic morphology was analyzed by using scanning electron microscopy (SEM) which refers to the JSM-6390A standard. This SEM analysis aims to see the phase spread of the bioplastic sample surface and examined the aggregation of cellulose fillers in their matrix.

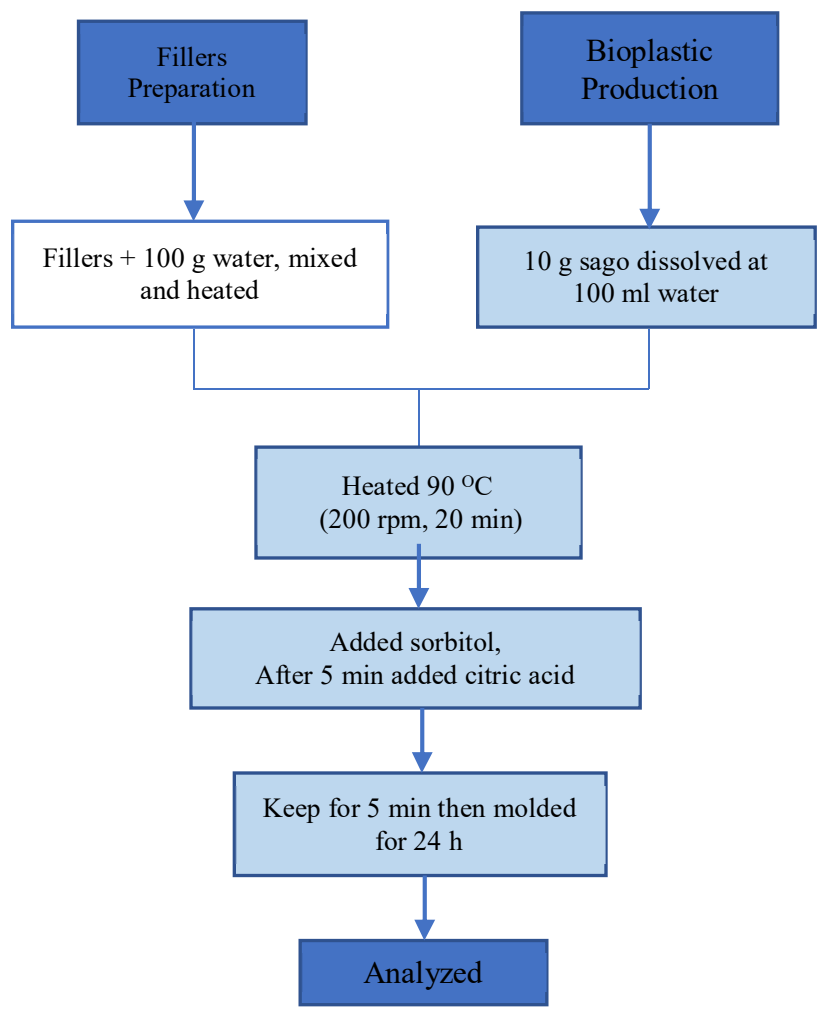

Fig. 1 Flowchart procedure of sago-based bioplastic.

\section{Experimental design}

Central composite design (CCD) was employed in this research to model the equations. Percentage of citric acid $\left(\mathrm{X}_{1}\right)$, plasticizer $\left(\mathrm{X}_{2}\right)$, and filler $\left(\mathrm{X}_{3}\right)$ were varied to describe the correlation among the parameters. They were the independent variables to figure out the earlier research related to bioplastic from sago starch. Tensile strength stands for response was dependent variable $\mathrm{Y} i$, while the concentration of citric acid $\left(\mathrm{x}_{1}\right)$, plasticizer $\left(\mathrm{x}_{2}\right)$, and filler $\left(\mathrm{x}_{3}\right)$ are listed in Table 1 . The experiment was conducted for twenty runs at three levels with the axial point on two responses (tensile strength for glycerol \& $\mathrm{CMC}\left(\mathrm{Y}_{1}\right)$ and sorbitol and $\left.\operatorname{MCC}\left(\mathrm{Y}_{2}\right)\right)$. The experimental data are given in Table 2. The relation among the parameters was described by using Response Surface Method (RSM).

TABLE I

THE RANGE AND LEVEL OF INDEPENDENT VARIABLES FOR BIOPLASTIC PRODUCTION

\begin{tabular}{cccc}
\hline $\begin{array}{c}\text { Level } \\
\text { code }\end{array}$ & $\begin{array}{c}\text { Citric Acid } \\
\left(\mathbf{x}_{\mathbf{1}}\right)\end{array}$ & Plasticizer $\left(\mathbf{x}_{2}\right)$ & Filler $\left(\mathbf{x}_{3}\right)$ \\
\hline $\mathbf{- 1}$ & 3 & 25 & \\
$\mathbf{0}$ & 6 & 30 & 15 \\
$\mathbf{1}$ & 9 & 35 & 20 \\
\hline
\end{tabular}

TABLE II

EXPERIMENTAL RESULT FOR BIOPLASTIC PRODUCT WHICH VARIED PLASTICIZER AND FILLER

\begin{tabular}{|c|c|c|c|c|c|}
\hline No. & $\begin{array}{c}\text { Citric } \\
\text { acid } \\
(\%), \mathbf{X}_{1}\end{array}$ & $\begin{array}{c}\text { Plastici } \\
\text { zer (\%), } \\
\mathbf{X}_{2}\end{array}$ & $\begin{array}{c}\text { Filler } \\
(\%), \\
\mathbf{X}_{3} \\
\end{array}$ & $\begin{array}{c}\text { Tensile } \\
\text { strength } \\
(\mathrm{MPa}), \mathrm{Y}_{1} \\
\end{array}$ & $\begin{array}{c}\text { Tensile } \\
\text { strength } \\
\text { (MPa), } Y_{2}\end{array}$ \\
\hline 1 & 3 & 25 & 15 & 6.24 & 9.31 \\
\hline 2 & 9 & 25 & 15 & 5.91 & 8.2 \\
\hline 3 & 3 & 35 & 15 & 5.59 & 6.3 \\
\hline 4 & 9 & 35 & 15 & 4.8 & 4.25 \\
\hline 5 & 3 & 25 & 25 & 8 & 10.26 \\
\hline 6 & 9 & 25 & 25 & 8.07 & 9.83 \\
\hline 7 & 3 & 35 & 25 & 7.09 & 8.49 \\
\hline 8 & 9 & 35 & 25 & 6.14 & 7.51 \\
\hline 9 & 0.955 & 30 & 20 & 7.68 & 15.84 \\
\hline 10 & 11.045 & 30 & 20 & 6.01 & 11.04 \\
\hline 11 & 6 & 21.59 & 20 & 6.3 & 10.13 \\
\hline 12 & 6 & 38.409 & 20 & 4.77 & 4.9 \\
\hline 13 & 6 & 30 & 11.59 & 5.65 & 5.13 \\
\hline 14 & 6 & 30 & 28.41 & 8.23 & 9.34 \\
\hline 15 & 6 & 30 & 20 & 5.16 & 13.26 \\
\hline 16 & 6 & 30 & 20 & 6.7 & 12.43 \\
\hline 17 & 6 & 30 & 20 & 6.21 & 10.75 \\
\hline 18 & 6 & 30 & 20 & 5.75 & 14.34 \\
\hline 19 & 6 & 30 & 20 & 6.04 & 11.46 \\
\hline 20 & 6 & 30 & 20 & 7.02 & 11.69 \\
\hline
\end{tabular}

* $Y_{I}$ showed the result for a condition using glycerol as plasticizer and CMC as filler; on the contrary, $Y_{2}$ for sorbitol as plasticizer and MCC as filler.

Quadratic equation produced empirical models for tensile strength for varied plasticizer and filler as shown in Equation 1 .

$$
\begin{aligned}
& \mathrm{Y}_{\mathrm{i}}=\beta_{o}+\beta_{1} x_{1}+\beta_{2} x_{2}+\beta_{3} x_{3}+\beta_{11} x_{1}^{2}+\beta_{22} x_{2}^{2}+ \\
& \beta_{33} x_{3}^{2}+\beta_{12} x_{1} x_{2}+\beta_{13} x_{1} x_{3}+\beta_{23} x_{2} x_{3}
\end{aligned}
$$

where $Y_{i}$ is response function, $\beta_{o}$ is intercept term, $\beta_{1}, \beta_{2}, \beta_{3}$ are linear effect, $\beta_{11}, \beta_{22}, \beta_{33}$ are quadratics effect and $\beta_{12}, \beta_{23}, \beta_{13}$ are interaction effect among the variables. Pvalue was applied to relate the effects of the variables with responses and the F-value was checked the validity of estimated model equation for tensile strength. RSM was analyzed by using STATISTICA version 7 program.

\section{RESULT AND DISCUSSION}

\section{A. Bioplastic Morphology}

The samples were assessed using Scanning Electron Microscope (SEM) to observe the surface structure and the filler's distribution on starch, as shown in Fig. 2. It is represented by $30 \%$ plasticizer, $28.41 \%$ of CMC filler, and $6 \%$ citric acid. Fig. 2a shows that $\mathrm{CMC}$ as the filler has not fully distributed on the surface, and CMC agglomerated in certain edible film spots. It is caused by the increase of filler content in the samples. The increasing agglomeration made the interaction between fillers and matrix weak [19]. On the other hand, the distribution of MCC as filler is shown in Fig. 2b. It was represented by $20 \%$ filler of MCC, $30 \%$ sorbitol as a plasticizer, and $9.5 \%$ citric acid. SEM shows a rough structure and an untidy but rigid one. 

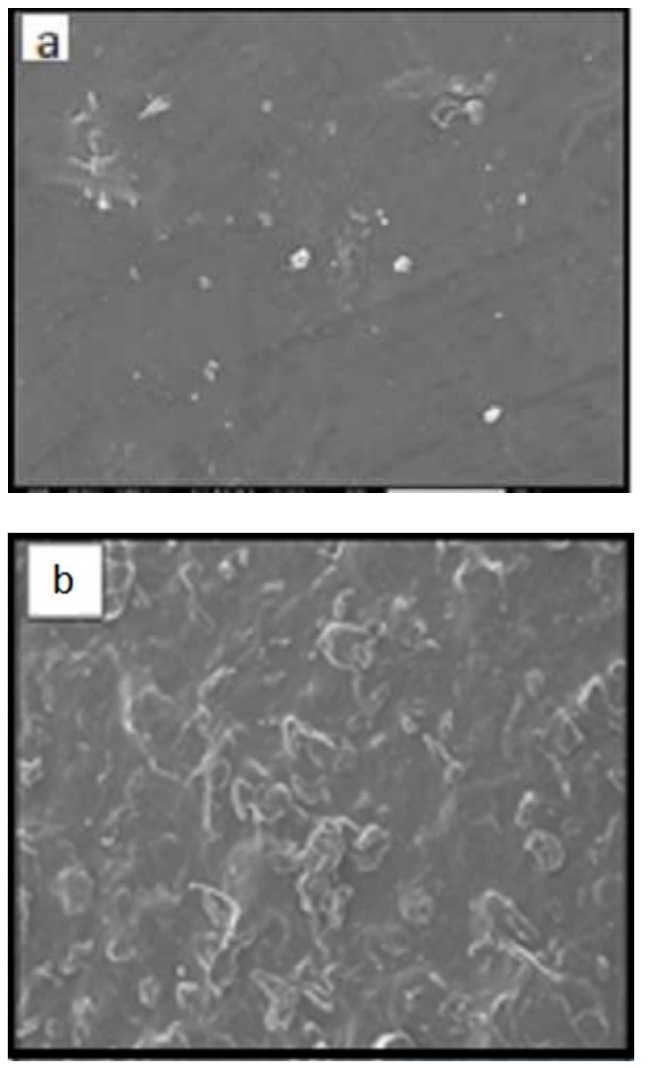

Fig. 2 SEM's result used (a) CMC and (b) MCC as filler for magnified 500 $\mu \mathrm{m}$

Since sorbitol has a more significant molecule, the matrix is occupied with hydrogen bonding, which disrupts polymer structure into an untidy structure [15], [20]. Agglomeration occurred in the matrix initiated the decreasing of tensile strength. It made the filler unable to support the tensile transfer evenly. It triggered unstable conditions for the enhancement filler mechanism [19] .

\section{B. Experimental Design and Statistical Analysis}

New model equations were produced from the experimental data laboratory to predict the tensile strength by using a statistical program. An ANOVA system has been employed to correlate the relation among the parameters [21]. The model equation for tensile strength by using glycerol as plasticizer and $\mathrm{CMC}$ as filler $\left(\mathrm{Y}_{1}\right)$ and sorbitol as plasticizer and $\mathrm{MCC}$ as filler $\left(\mathrm{Y}_{2}\right)$ are given in Equations 2 and 3, respectively.

$$
\begin{aligned}
& y_{1}=-0.5171-0.1229 X_{1}+0.5847 X_{2} \\
&-0.1436 X_{3}+0.01279 X_{1}^{2} \\
&-0.0085 X_{2}^{2}+0.0114 X_{3}^{2} \\
&-0.0123 X_{1} X_{2}+0.002 X_{1} X_{3} \\
&-0.0054 X_{2} X_{3} \\
& \\
& Y_{2}=-75.9179-0.4169 X_{1}+4.1832 X_{2} \\
&+ 2.9854 X_{3}+0.0158 X_{1}^{2} \\
&-0.0781 X_{2}^{2}-0.0821 X_{3}^{2} \\
&-0.0124 X_{1} X_{2}+0.0146 X_{1} X_{3} \\
&+ 0.0143 X_{2} X_{3}
\end{aligned}
$$

Regression analysis for tensile strength is depicted in Table 2. Analysis of variance (ANOVA) was used with a 5\% level of significance, and the model was set up by checking the F- value. The negative sign in the front term indicated the antagonist effect of the variables [22]. Table 3 shows that $F$ value was higher than the $\mathrm{F}$ table, meaning the variables significantly affected tensile strength and rejected the null hypothesis.

The coefficient of correlation, $\mathrm{R}^{2}$, was accepted if it higher than 0.75 , which implied the relation between the experimental and predicted value of tensile strength. Figure 3 illustrates the predicted and experimental value of tensile strength for $\mathrm{Y} 1$, which uses glycerol as plasticizer and CMC as filler, and $\mathrm{Y}_{2}$, sorbitol as a plasticizer, and $\mathrm{MCC}$ as filler. It showed the close agreement between the observed and

\begin{tabular}{|c|c|c|c|c|c|}
\hline Mode & 莞 & $=$ & 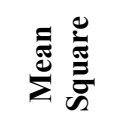 & $\begin{array}{c}\mathbf{F} \\
\text { value }\end{array}$ & $\begin{array}{c}F \\
0.05\end{array}$ \\
\hline \multicolumn{6}{|l|}{$\begin{array}{l}\text { Tensile } \\
\text { strength } \\
\left(Y_{1}\right)\end{array}$} \\
\hline Regression & 17.7976 & 9 & 1.9775 & & \\
\hline Residual & 2.5253 & 10 & 0.2525 & 7.8308 & 3.02 \\
\hline Total & 20.3229 & 19 & & & \\
\hline \multicolumn{6}{|l|}{$\begin{array}{l}\text { Tensile } \\
\text { strength } \\
\left(Y_{2}\right)\end{array}$} \\
\hline Regression & 167.8598 & 9 & 18.6511 & & \\
\hline Residual & 15.9357 & 10 & 1.5935 & 11.7039 & 3.02 \\
\hline Total & 183.7956 & 19 & & & \\
\hline
\end{tabular}
predicted value and yield $\mathrm{R}^{2}$ was $0.875\left(\mathrm{Y}_{1}\right)$ and 0.913 . It indicated that the proposed equation was fitted to experimental data.

TABLE III

ANOVA FOR TENSILE STRENGTH

TABLE IV

THE SigNIFICANCE OF COEFFICIENT ESTIMATED FOR TENSILE STRENGTH (Y1)

\begin{tabular}{ccccccc}
\hline$\underset{\Xi}{\stackrel{\Xi}{\Xi}}$ & Effect & $\begin{array}{l}\text { Sum of } \\
\text { Squares }\end{array}$ & df & $\begin{array}{l}\text { Mean } \\
\text { Square }\end{array}$ & F value & p-value \\
$\mathbf{X}_{\mathbf{1}}$ & -0.7042 & 1.6931 & 1 & 1.69307 & 6.7044 & 0.02698 \\
$\mathbf{X}_{\mathbf{1}}{ }^{2}$ & 0.5033 & 0.9122 & 1 & 0.91224 & 3.61244 & 0.08653 \\
$\mathbf{X}_{\mathbf{2}}$ & -1.0504 & 3.7679 & 1 & 3.76785 & 14.9204 & 0.00315 \\
$\mathbf{X}_{\mathbf{2}}{ }^{2}$ & -0.4231 & 0.6452 & 1 & 0.64516 & 2.5548 & 0.14104 \\
$\mathbf{X}_{\mathbf{3}}$ & 1.6253 & 9.0202 & 1 & 9.02021 & 35.7194 & 0.00014 \\
$\mathbf{X}_{\mathbf{3}}{ }^{2}$ & 0.5702 & 1.1719 & 1 & 1.17188 & 4.6405 & 0.05666 \\
$\mathbf{X}_{\mathbf{1}} \mathbf{X}_{\mathbf{2}}$ & -0.3700 & 0.2738 & 1 & 0.27380 & 1.0842 & 0.3223 \\
$\mathbf{X}_{\mathbf{1}} \mathbf{X}_{\mathbf{3}}$ & 0.0600 & 0.0072 & 1 & 0.00720 & 0.0285 & 0.8693 \\
$\mathbf{X}_{\mathbf{2}} \mathbf{X}_{\mathbf{3}}$ & -0.2700 & 0.1458 & 1 & 0.14580 & 0.5774 & 0.4649 \\
\hline
\end{tabular}

Table 4 and 5 illustrate the significant variable among the variables for two responses $\left(\mathrm{Y}_{1}\right.$ and $\left.\mathrm{Y}_{2}\right)$. The significance of coefficients for $\mathrm{Y}_{1}$ depicted that concentration of citric acid, plasticizer, and filler has a significant effect on tensile strength among other variables. It also found that there was no significant influence for interaction between variables and 
the quadratic mode. The higher F-value was concentration filler, and it fitted for $p$-value.

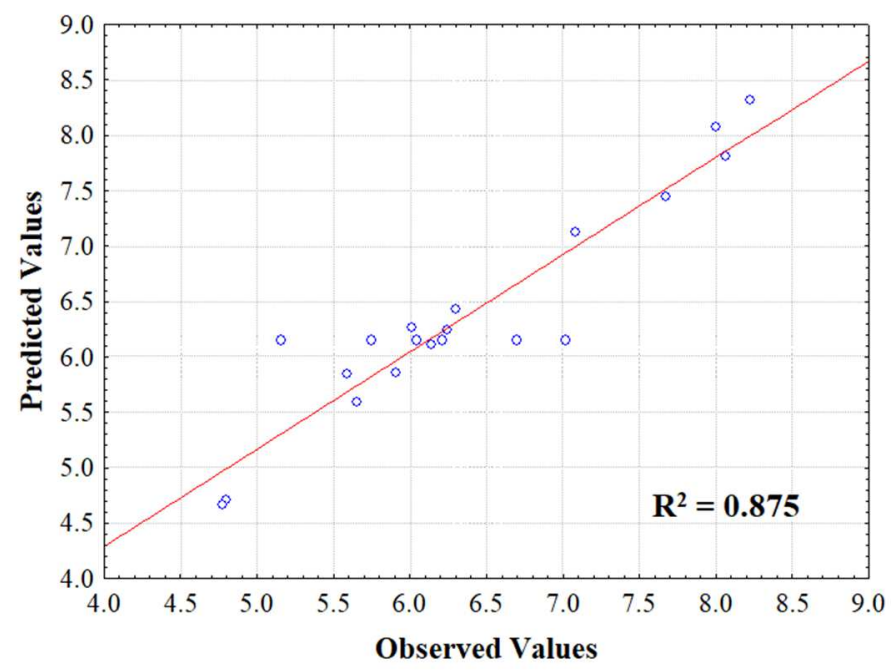

(a)

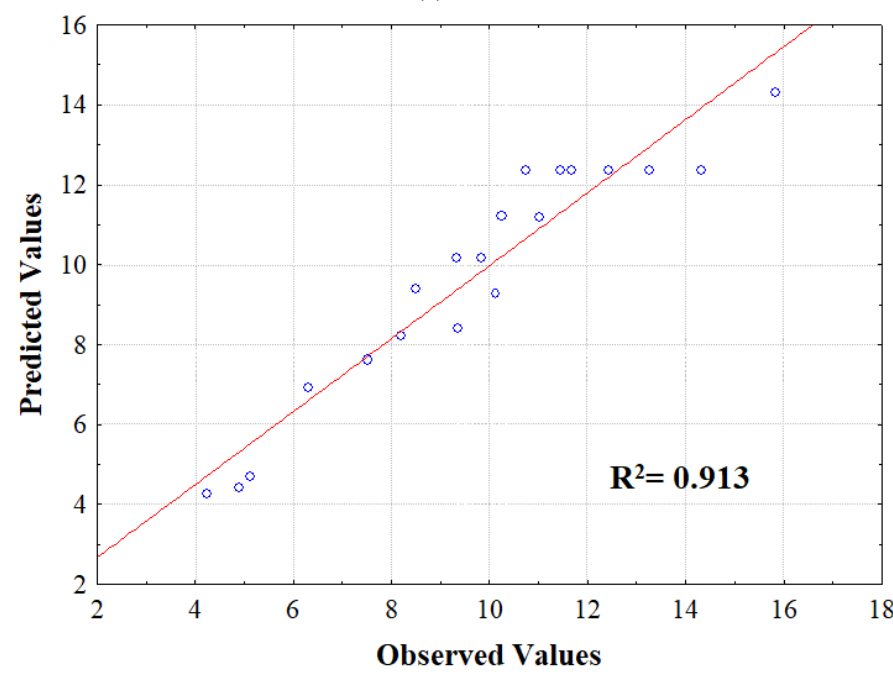

(b)

Fig. 3 Observed vs predicted tensile strength in bioplastic product (a) for response $\mathrm{Y}_{1},(\mathrm{~b})$ response $\mathrm{Y}_{2}$

Table 5 shows $\mathrm{x}_{1}, \mathrm{x}_{2}, \mathrm{x}_{2}^{2}, \mathrm{x}_{3}, \mathrm{x}_{3}^{2}$ acted as significant variables for $Y_{2}$. It had expected that $F$ value and $P$ value had a significant effect on $\mathrm{x}_{1}, \mathrm{x}_{2}, \mathrm{x}_{2}{ }^{2}, \mathrm{x}_{3}, \mathrm{x}_{3}{ }^{2}$ which named for concentration of citric acid, plasticizer linear and quadratic, filler in linear and quadratic. Filler concentration has higher F-value than other variables and it fitted the p-value.

Student t-distribution was applied to estimate the value of equation parameter and error standard to see the confidence limit, while $\mathrm{p}$ value was employed to check the significance of variables for tensile strength properties. Both tests were used to seek the significant effect for each variable in the process; this correlation is illustrated in Fig. 4. Fig. 4 (a) depicts that the significant concentration of filler, plasticizer and citric acid with $\mathrm{p}>0.05$, on the other hands, Fig. 4(b) illustrates the interaction of quadratic filler, plasticizer and linear variable of plasticizer, filler and citric acid which have significance influence on tensile strength.
TABLE V

THE SignifiCANCE OF COEFFICIENT Estimated FOR TENSILE STRENGTH (Y2)

\begin{tabular}{lrrrrrr}
\hline Source & Effect & $\begin{array}{l}\text { Sum of } \\
\text { Squares }\end{array}$ & $\mathbf{d f}$ & $\begin{array}{l}\text { Mean } \\
\text { Square }\end{array}$ & F value & p-value \\
\hline $\mathbf{X}_{\mathbf{1}}$ & -1.8515 & 11.7033 & 1 & 11.7033 & 7.34406 & 0.021934 \\
$\mathbf{X}_{\mathbf{1}}{ }^{2}$ & 0.2838 & 0.2901 & 1 & 0.2901 & 0.18204 & 0.678662 \\
$\mathbf{X}_{\mathbf{2}}$ & -2.9066 & 28.8463 & 1 & 28.8463 & 18.10164 & 0.001677 \\
$\mathbf{X}_{\mathbf{2}}{ }^{2}$ & -3.9053 & 54.9591 & 1 & 54.9591 & 34.48798 & 0.000157 \\
$\mathbf{X}_{\mathbf{3}}$ & 2.2128 & 16.7188 & 1 & 16.7188 & 10.49137 & 0.008884 \\
$\mathbf{X}_{\mathbf{3}}{ }^{2}$ & -4.1026 & 60.6652 & 1 & 60.6652 & 38.06866 & 0.000106 \\
$\mathbf{X}_{\mathbf{1}} \mathbf{X}_{\mathbf{2}}$ & -0.3725 & 0.2775 & 1 & 0.2775 & 0.17414 & 0.685272 \\
$\mathbf{X}_{\mathbf{1}} \mathbf{X}_{\mathbf{3}}$ & 0.4375 & 0.3828 & 1 & 0.3828 & 0.24022 & 0.634620 \\
$\mathbf{X}_{\mathbf{2}} \mathbf{X}_{\mathbf{3}}$ & 0.7175 & 1.0296 & 1 & 1.0296 & 0.64610 & 0.440198 \\
\hline
\end{tabular}

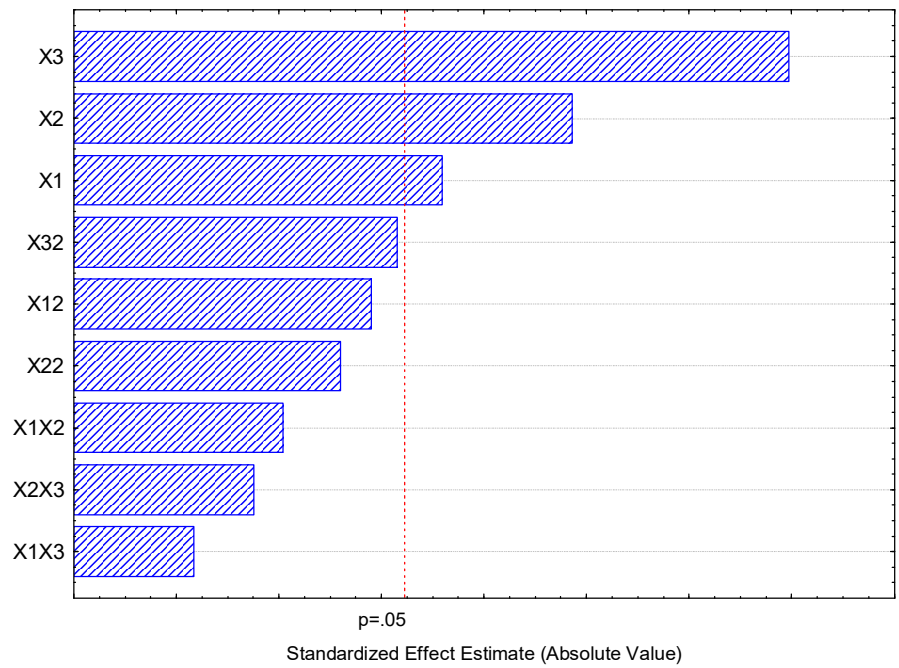

(a)

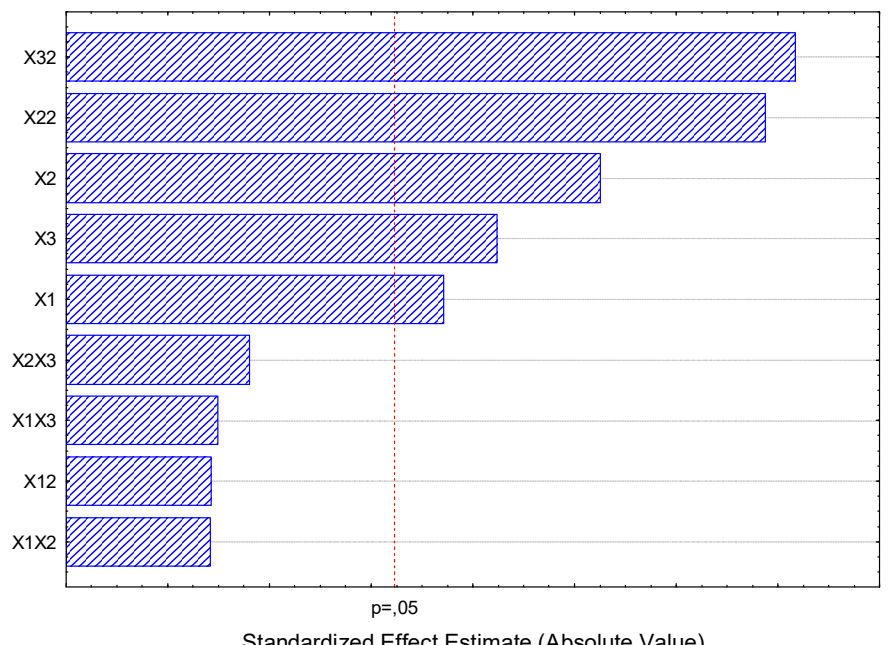

(b)

Fig. 4 Pareto chart of response for $Y_{1}(a)$ and $Y_{2}$ (b)

The higher significance effect is shown by quadratic filler in Figure 4. The lowest $p$-value $(p<0.05)$ indicated the interaction between citric acid and filler (Fig. 4a) and interaction between citric acid and plasticizer for tensile strength properties. 


\section{Interaction of Variables for Tensile Strength Properties}

All the three-dimensional responses surface is illustrated in Fig. 5 and 6 . The interactive effect of each variables with respect to tensile strength were analyzed. Fig. 5 shows increased plasticizer has significance effect and influence the tensile strength than increased citric acid. The lowest tensile strength was achieved at 3\% citric acid, $15 \%$ filler and 35\% plasticizer about $5.59 \mathrm{MPa}$.

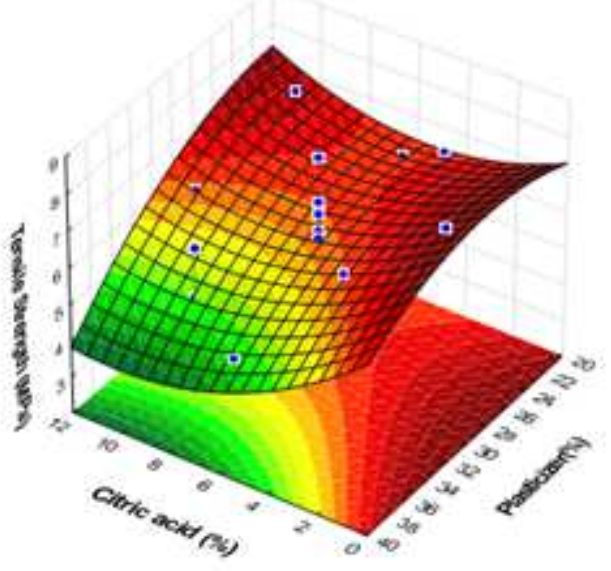

(a)

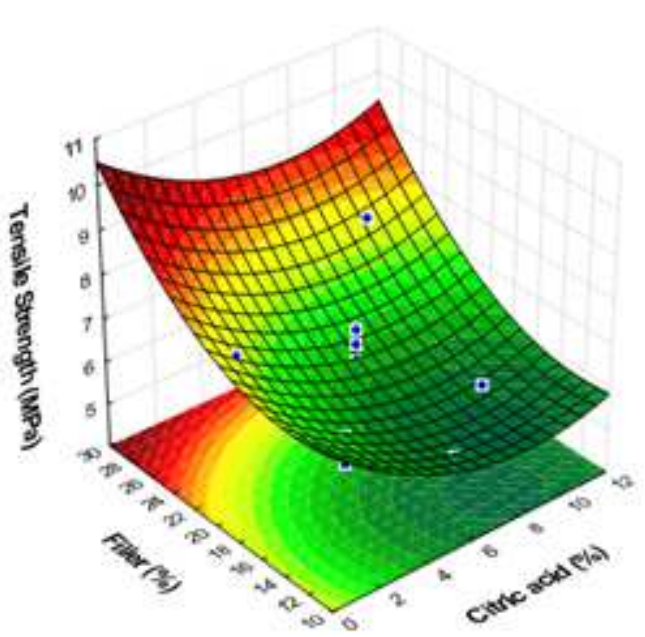

(b)

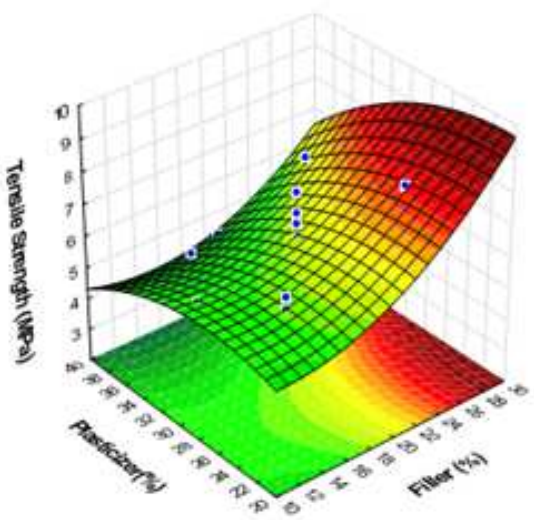

(c)

Fig. 5 Response fitted surface area of tensile strength for $\mathrm{Y}_{1}$ (a) citric acid and plasticizer, (b) citric acid and filler (c) filler and plasticizer.

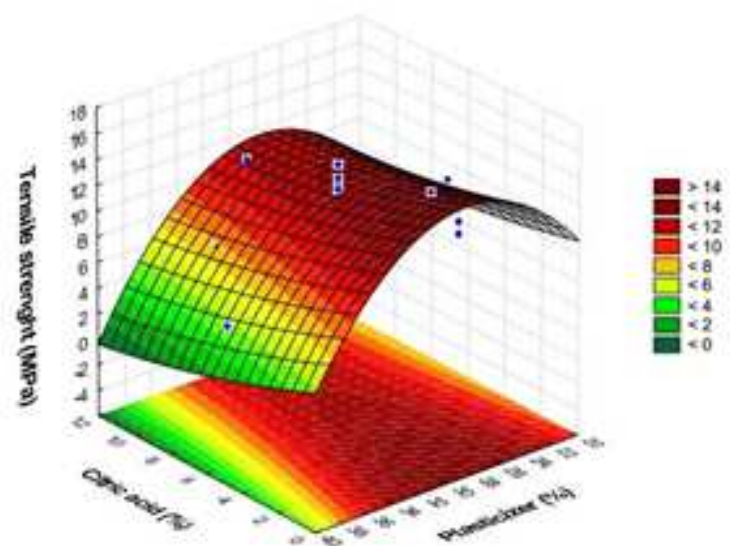

(a)

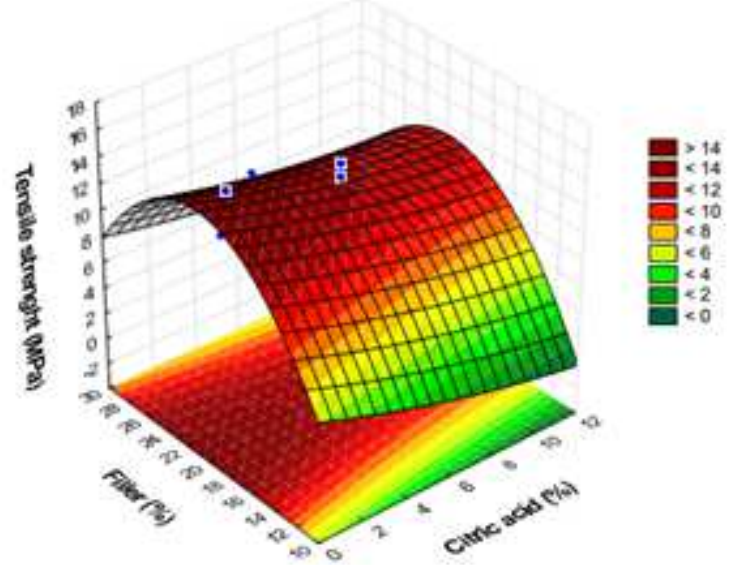

(b)

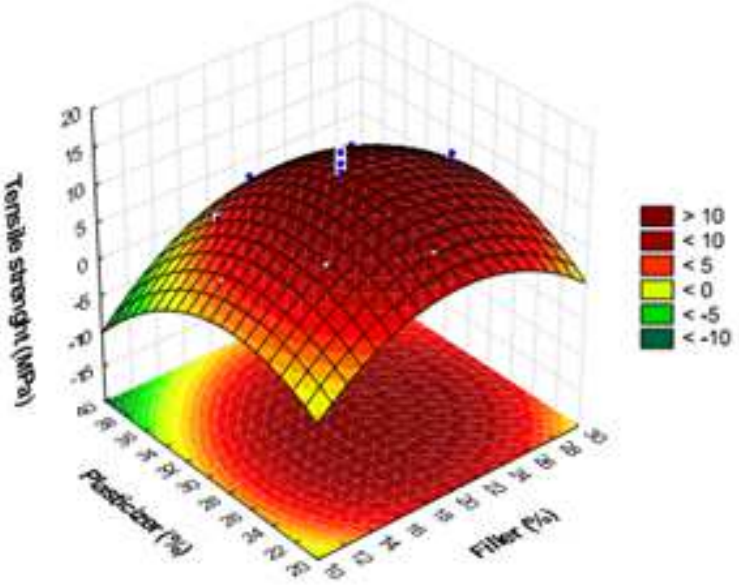

(c)

Fig. 6 Response fitted surface area of tensile strength, $\mathrm{Y}_{2}$, (a) Citric acid and plasticizer (b) citric acid and filler (c) Filler and plasticizer.

The tensile strength value was about 4.77-8.23 MPa. Fig. 5 shows that the concentration of filler and plasticizer has a significant effect on increased tensile strength. According to [23], CMC interacted and substituted the hydrogen bond generated a dense blending product structure. The intensive bonding between starch and $\mathrm{CMC}$ made deprotonation of CMC's carboxyl group and stretching of carbonyl (-CO) group presence. This condition enhanced the mechanical properties of the edible film, including tensile strength. Another study [24] found that glycerol made a polymorphic 
transition that shrinks the starch's crystallites. This hydroxyl group caused the increased film strength. The high concentration of plasticizer (in the case of; glycerol) decreased the molecule's surface tension that arranged matrix film, thus decreasing edible film [25]. Fig. 5 (a and b) illustrates that the concentration of citric acid has not significantly affected tensile strength.

From Fig. 6 ( $a, b$ and $c$ ) illustrates that the concentration of plasticizer and filler has a significant effect on tensile strength. It was also reported by another studies [15], [23] where they mentioned glycerol and sorbitol contributed through hydrogen bonding to make a strong interaction bonding between polymer and plasticizer. Moreover, Martinez et al., [15] reported that the increasing concentration of sorbitol or glycerol can decrease the puncture strength since the plasticizer affects the movement of the polymer chains.

The dome graphs display high tensile strength in higher plasticizers (in terms of sorbitol) and filler (MCC). Maximum tensile strength was achieved at $30 \%$ plasticizer and $20 \%$ filler for $15.84 \mathrm{MPa}$ in the dome's peak whereas from the center point. The citric acid (3-9\%) depicts that the higher concentration of citric acid has not significantly affected tensile strength.

\section{CONCLUSIONS}

The model equation for tensile strength by using glycerol as plasticizer and $\mathrm{CMC}$ as filler $\left(\mathrm{Y}_{1}\right)$ and sorbitol as plasticizer and $\mathrm{MCC}$ as a filler $\left(\mathrm{Y}_{2}\right)$ are given in Equations 2 and 3, respectively. It was found that citric acid as cross-linking agent has higher tensile strength than without citric acid and that sorbitol and microcrystalline cellulose (MCC) has higher tensile strength than glycerol and carboxymethylcellulose (CMC). Also, it showed that plasticizer concentration had a significant effect on tensile strength. The best edible film composition consists of microcrystalline cellulose (MCC) $20 \%$ $\mathrm{w} / \mathrm{w}$, sorbitol $30 \% \mathrm{w} / \mathrm{w}$ with citric acid $0.95 \% \mathrm{w} / \mathrm{w}$. The best tensile strength value was $15.84 \mathrm{MPa}$.

\section{ACKNOWLEDGMENT}

The authors are grateful to Research and Community Service Board of Universitas Riau that funded this research.

\section{REFERENCES}

[1] P. Lestari and Y. Trihadiningrum, "The impact of improper solid waste management to plastic pollution in Indonesian coast and marine environment," Mar. Pollut. Bull., vol. 149, no. April, p. 110505, 2019.

[2] C. Zhang, C. Wang, G. Cao, D. Wang, and S. Ho, "A sustainable solution to plastics pollution: An eco-friendly bioplastic fi $1 \mathrm{~m}$ production from high-salt contained Spirulina sp . residues," J. Hazard. Mater., vol. 388, no. November 2019, p. 121773, 2020.

[3] P. He, L. Chen, L. Shao, H. Zhang, and F. Lü, "Municipal solid waste (MSW)landfill: A source of microplastics? -Evidence of microplastics in landfill leachate," Water Res., vol. 159, pp. 38-45, 2019.

[4] A. Shafqat, A. Tahir, A. Mahmood, A. B. Tabinda, A. Yasar, and A. Pugazhendhi, "A review on environmental significance carbon footprints of starch based bio-plastic: A substitute of conventional plastics," Biocatal. Agric. Biotechnol., vol. 27, no. May 2019, p. $101540,2020$.

[5] A. Shafqat, N. Al-zaqri, A. Tahir, and A. Alsalme, "Saudi Journal of Biological Sciences Synthesis and characterization of starch based bioplatics using varying plant-based ingredients, plasticizers and natural fillers," Saudi J. Biol. Sci., no. xxxx, 2020.
[6] Y. Zoungranan, E. Lynda, K. K. Dobi-Brice, E. Tchirioua, C. Bakary, and D. D. Yannick, "Influence of natural factors on the biodegradation of simple and composite bioplastics based on cassava starch and corn starch," J. Environ. Chem. Eng., vol. 8, no. 5, p. 104396, 2020.

[7] V. Florencia, O. V. López, and M. A. García, "Exploitation of byproducts from cassava and ahipa starch extraction as filler of thermoplastic corn starch," Compos. Part B Eng., vol. 182, no. November 2019, 2020.

[8] M. Hasjim Bintoro et al., "Mix Farming Based on Sago Palm in Meranti Island District, Riau Province, Indonesia," Alınteri Zirai Bilim. Derg., no. June 2020.

[9] H. Abral et al., "A simple method for improving the properties of the sago starch films prepared by using ultrasonication treatment," Food Hydrocoll., vol. 93, no. August 2018, pp. 276-283, 2019.

[10] L. D. Pérez-Vergara, M. T. Cifuentes, A. P. Franco, C. E. PérezCervera, and R. D. Andrade-Pizarro, "Development and characterization of edible films based on native cassava starch, beeswax, and propolis," NFS J., vol. 21, no. August, pp. 39-49, 2020.

[11] R. Farajpour, Z. Emam Djomeh, S. Moeini, H. Tavahkolipour, and S. Safayan, "Structural and physico-mechanical properties of potato starch-olive oil edible films reinforced with zein nanoparticles," Int. J. Biol. Macromol., vol. 149, pp. 941-950, 2020.

[12] B. Ghanbarzadeh, H. Almasi, and A. A. Entezami, "Physical properties of edible modified starch/carboxymethyl cellulose films," Innov. Food Sci. Emerg. Technol., vol. 11, no. 4, pp. 697-702, 2010.

[13] A. Zuraida, Y. Yusliza, H. Anuar, and R. Mohd Khairul Muhaimin, "The effect of water and citric acid on sago starch bio-plastics," Int. Food Res. J., vol. 19, no. 2, pp. 715-719, 2012.

[14] K. Wilpiszewska and Z. Czech, "Citric acid modified potato starch films containing microcrystalline cellulose reinforcement - Properties and application," Starch/Staerke, vol. 66, no. 7-8, pp. 660-667, 2014.

[15] L. Ballesteros-Mártinez, C. Pérez-Cervera, and R. Andrade-Pizarro, "Effect of glycerol and sorbitol concentrations on mechanical, optical, and barrier properties of sweet potato starch film," NFS J., vol. 20, no. April, pp. 1-9, 2020.

[16] R. Priyadarshi, Sauraj, B. Kumar, and Y. S. Negi, "Chitosan film incorporated with citric acid and glycerol as an active packaging material for extension of green chilli shelf life," Carbohydr. Polym., vol. 195, no. December 2017, pp. 329-338, 2018.

[17] K. Wilpiszewska, A. K. Antosik, and M. Zdanowicz, "The Effect of Citric Acid on Physicochemical Properties of Hydrophilic Carboxymethyl Starch-Based Films," J. Polym. Environ., vol. 27, no. 6, pp. 1379-1387, 2019.

[18] W. Ma, S. Rokayya, L. Xu, X. Sui, L. Jiang, and Y. Li, "PhysicalChemical Properties of Edible Film Made from Soybean Residue and Citric Acid," J. Chem., vol. 2018, 2018.

[19] C. S. Baek, K. H. Cho, and J. W. Ahn, "Effect of grain size and replacement ratio on the plastic properties of precipitated calcium carbonate using limestone as raw material," J. Korean Ceram. Soc., vol. 51, no. 2, pp. 127-131, 2014.

[20] S. Pramod, K. S. Rajput, and K. S. Rao, "Immunolocalization of $\beta$-(14)-D-galactan, xyloglucans and xylans in the reaction xylem fibres of Leucaena leucocephala (Lam.) de Wit," Plant Physiol. Biochem., vol. 142, no. March, pp. 217-223, 2019.

[21] S. P. Utami and N. S. Amin, "Optimization of glucose conversion to 5-hydroxymethylfulfural using [BMIM]Cl with ytterbium triflate," Ind. Crops Prod., vol. 41, no. 1, pp. 64-70, 2013.

[22] M. Shahedi, M. Yousefi, Z. Habibi, M. Mohammadi, and M. A. As'habi, "Co-immobilization of Rhizomucor miehei lipase and Candida antarctica lipase B and optimization of biocatalytic biodiesel production from palm oil using response surface methodology," Renew. Energy, vol. 141, pp. 847-857, 2019.

[23] K. M. Tavares, A. de Campos, B. R. Luchesi, A. A. Resende, J. E. de Oliveira, and J. M. Marconcini, "Effect of carboxymethyl cellulose concentration on mechanical and water vapor barrier properties of corn starch films," Carbohydr. Polym., vol. 246, no. June, p. 116521, 2020.

[24] D. Sagnelli et al., "All-natural bio-plastics using starch-betaglucan composites," Carbohydr. Polym., vol. 172, pp. 237-245, 2017.

[25] Y. P. M. Paradika, "Effect of Plasticizer and Chitosan Composition on the Plastic Biodegradable Quality from Starch Cassava Rubber (Manihot Glaziovii) as Alternative Plastic," Aasic.Org, pp. 83-88, 2017. 